\title{
Boundaries of Belonging
}

In October 1936, the British Resident Frederick Chapman, or "Freddie" as he was known by his close associates, received an invitation to a game of soccer from a team calling themselves Lhasa United. The British Diplomatic Mission in Lhasa, unable to resist such a summons, hastily cobbled together a team of four British officials, four of their Sikkimese clerks, and a few of their Tibetan servants. The Mission Marmots, as the British called themselves, quickly came together as a team ready for all challengers. ${ }^{1}$ When the British team arrived at the field, two miles past the Nörbulingka Summer Palace, they found a large crowd and a carefully marked out pitch as well as their opponents. Decked in "garish harlequincoloured silk shirts with the initials 'L.U.' sewn onto their pockets," Lhasa United were, as one British official later observed, "a remarkable looking team, and certainly needed to be 'United!' There was a tough-looking Nepali soldier, a Chinese tailor, three bearded Ladakhis wearing red fezzes - the most hirsute being the goal-keeper, a Sikkimese." ${ }^{2}$ The final score was 1-o in favor of the British. That fall, a total of four teams organized themselves to play the occasional match. While British officials would later insist they remained undefeated, others remembered the results differently. ${ }^{3}$ In addition to Lhasa United and the Mission Marmots, a team of young Tibetan officials and clerks known as the Kudraks (Tib. sku drag), or the Aristocrats, joined the competition sporting silk uniforms adorned with a snow lion. The fourth and final team was composed wholly of Lhasa Muslims, referred to by the British simply as the "Lhasa Mohammedans."

The four teams neatly reproduced Lhasa's main social divisions, and the matches quickly turned into elaborate social affairs with several matches occurring in quick succession that fall. The impromptu matches were brought to an abrupt end late 


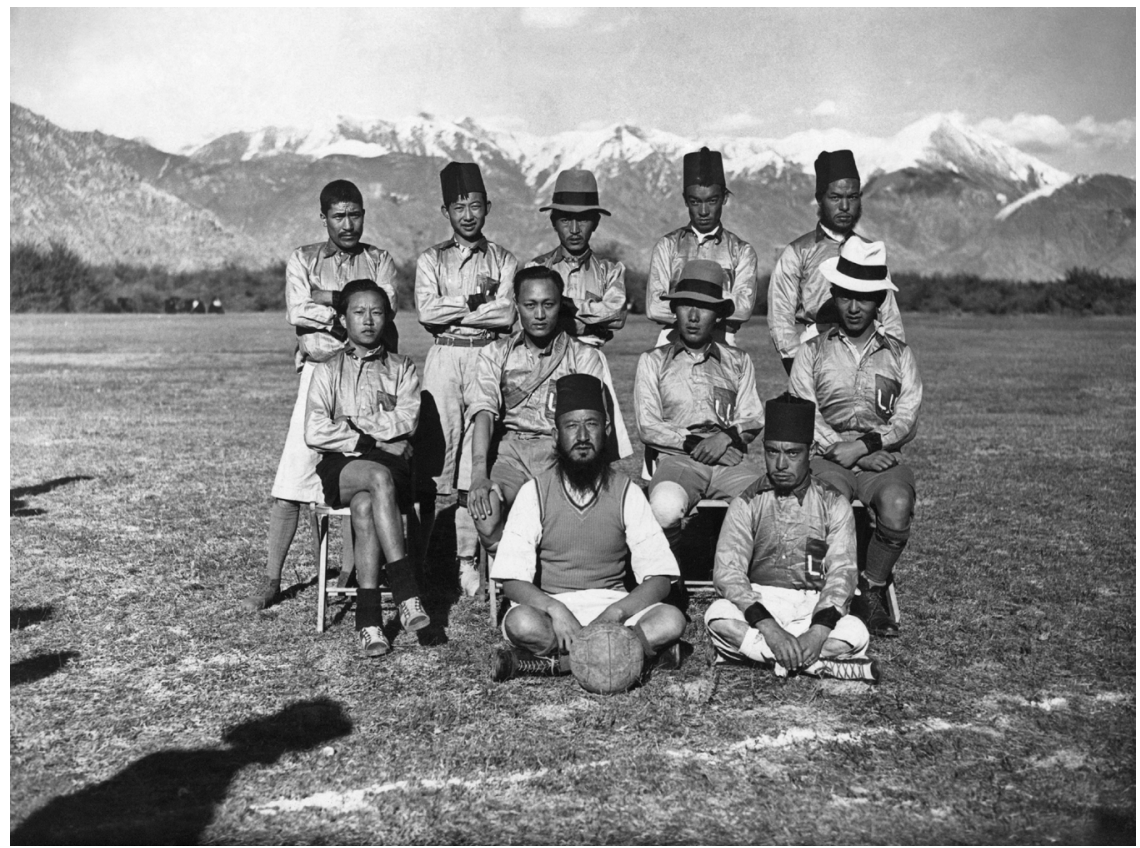

The Lhasa United soccer team, composed of Tibetan Sikkimese, Ladhaki, and Nepalese players, whose league opponents were such teams as the Mission Marmots, the Aristocrats, and the Lhasa Muslims. October 20, 1936. Source: Pitt Rivers Museum, University of Oxford.

one October evening when the wooden goalposts were pilfered-perhaps to be used as firewood. The missing goalposts aside, plummeting temperatures had made it too uncomfortable to play, so it was decided to wait until spring to find replacement goalposts and recommence the matches.

The following year the matches grew in popularity, attracting an ever greater number of spectators. Curious onlookers flowed out to the field near Tsidrunglingka Park (Tib. rtse drung gling $\mathrm{ka}$ ) by the river in the southeast part of Lhasa to watch the foreign games. The season wore on until one day, just as a match was about to get under way, a rabbit ran onto the field. As this is deemed one of twenty-one ill omens (Tib. ltas ngan), several onlookers gasped and attempted to postpone the match. They were dismissed as being overly superstitious, however, and the game got under way with no immediate ominous consequences. In the second half, just as the Kudraks took a 2-1 lead over the Marmots, a fierce hailstorm abruptly materialized. Great gusts of wind shredded the spectators' large umbrellas. Hail pelted the area with pellets so large that nearby crops were seriously damaged.

Many officials, already disquieted by the growing popularity and influence of foreign pastimes, took this opportunity to bring the entire matter before 
the government. The next day, the Tibetan Assembly (Tib. tshogs ' $d u$ ) formally deliberated the issue. While advocates of the game argued its social and health benefits, its critics called it sacrilegious and expressed concern that such games disturbed the local gods. One official heatedly declared, "It was like they were kicking the head of Buddha around the field." After several hours of debate, the regent's secretariat (Tib. shöga) declared soccer improper, ordered that no further matches be permitted, and directed that the involved players be fined several sang of gold. ${ }^{4}$

The impromptu soccer league presents an enthralling snapshot of the rarely scrutinized divisions within twentieth-century Lhasa society: the Kudraks, young lay Tibetan officials, demonstrating a keen interest in a foreign sport introduced by the British to the Lhasa valley; and the Lhasa United team, composed of unambiguously "foreign residents" but "united" and familiar enough to be welcomed into the league. Yet it is the final team, the Lhasa Mohammedans, that is perhaps the most beguiling. Considered neither foreign residents, like the Ladakhi Muslims, nor nominal British subjects, like the Sikkimese, the Lhasa Mohammedan team was composed of Tibetan subjects who were almost certainly not foreign. ${ }^{5}$ The creation of the soccer league offers a valuable corrective to the frequency with which one encounters descriptions of Tibet as singularly Buddhist, isolated, and impervious to external influences. The organic manner in which the Lhasa Muslims and Ladakhi Muslims played on separate teams-one foreign and one Tibetan-also raises the question of how a Tibetan Muslim community thrived in a land so often portrayed as monolithically Buddhist.

Situated on a high mountain plateau bounded by steep peaks, Tibet is undeniably remote. Despite this remoteness, Tibet has been, through a diverse set of commercial, artistic, and cultural interactions, consistently and profoundly interconnected with the rest of Asia. ${ }^{6}$ Although the impression of Tibet as a "closed country" from the nineteenth century on lingers in the popular imagination of Tibet, Armenian and Russian merchants in the sixteenth century regularly crisscrossed Tibet to Lhasa, Shigatse, and Siling (Ch. Xining), as did half a dozen or so European missionaries by the seventeenth century. Nor should we limit our definition of "foreigners" simply to non-Asians. More familiar to Tibetans but nonetheless undeniably foreign were the far larger numbers of trans-Himalayan peoples of Kashmir, Sikkim, Bhutan, and Nepal who contributed to shaping Tibetan society, as traders, religious scholars, architects, and myriad other specialists. Tibetan leaders welcomed foreigners and their skills. Mongolians aided militarily; Nepalese, artistically; and Kashmiris, commercially. Foreigners in Tibet were embraced, accepted, and appreciated, not reviled, vilified, or segregated. ${ }^{7}$

The Tibetan Muslim community, called Khache (Tib. khaché), reflects a paradox of indigeneity. It comprises a people who indisputably originated outside of Tibet but who swiftly embraced Tibetan culture, excelled linguistically, artistically, and commercially as Tibetans, who settled in central Tibet and, from the seventeenth 
century on, were accepted as Tibetan. It is a community that has its origins in the disparate cultural traditions of South, Central, and East Asia, yet remains undeniably Tibetan; that was renowned among the Tibetan elite for its mastery of the elaborate honorific-laden Tibetan language, yet consistently classified as nonTibetan in foreign descriptions of Tibet. And finally, it is a community that strikes at the heart of most popular definitions of Tibetans as exclusively Buddhist.

Foreign travelers' accounts also usefully augment Tibetan documents by highlighting the ethnic and racial diversity of daily life in Tibet. The French missionary Évariste Huc's Travels in Tartary, Thibet and China, 1844-1846 is perhaps the preeminent example of this genre. His account provides a dazzling portrait of mid-nineteenth-century Lhasa capturing the unique cosmopolitanism that typified the quotidian life of Tibet's capital.

In the town [of Lhasa] itself, the nature of the population has an altogether different character; with shouting, a hustle and bustle, and pushing and shoving, with each person intent on pursuing their next purchase or sale with an ardent zeal. Commerce and sacred devotion tempting a steady stream of foreigners, rendering this city as a gathering point of all the peoples of Asia; the streets are constantly crowded with pilgrims, traders, so that one observes an endless variety of facial features, attire and languages. For the large part this immense multitude is transitory, renewing itself on a daily basis. The permanent population of Lhasa consists of Tibetans, Newaris [Nepalis], Khache [Muslims] and Chinese. ${ }^{8}$

Huc's description of Lhasa's vibrant street life is striking in its meticulous attention to the city's ethnocultural diversity. Despite having arrived with almost no prior knowledge of Tibet and only a modicum of Tibetan, his sharp eye and his attentiveness to the city's rhythms and flows made his account of Tibetan life among the best records we have of daily life in Lhasa and central Tibet. ${ }^{9} \mathrm{He}$ is also one of only a handful of foreigners who, prior to the twentieth century, both resided in Lhasa for an extended period and wrote about it. It is thus significant that Huc devotes considerable attention to the Khache and returns to them consistently as a reference point in descriptions of other groups and social activities.

Even though Huc's description of Lhasa and Chapman's account of the soccer matches were written nearly a century apart, they both demonstrate that far from insulated, Tibet had vigorous and active interactions with an array of polities and peoples from across Asia. As the anthropologist Enseng Ho has suggested in his reflections on Asia's inter-Asian dimensions, the "inter-Asian world was suffused with such spatially broad and patterned engagements between mobile societies to a degree that we have forgotten and no longer know." 10

From a Tibetan perspective, the Khache's conspicuous presence is not nearly as surprising. Geoffrey Samuel's landmark study of Tibetan culture, society, and religion, Civilized Shamans, advances just such a conclusion. His analysis is at its 
core a multithemed soliloquy positing a single point-that "premodern Tibet contained a greater variety of social and political formations than is often appreciated." ${ }^{11}$ Reflecting this ethnic and regional diversity, the Khache communities exist in virtually all areas of Tibet: as far west as Srinagar in Kashmir, as far east as Dartsedo (Ch. Kangding) in Kham, as far north as Labrang Monastery in Amdo, and as far south as the Himalayan hill towns of Kalimpong and Darjeeling in northern India. ${ }^{12}$ Similar to Samuel's work, a central goal of this study is to pioneer a thick transregional history of the Tibetan Muslims written against the grain of state-based national histories of Asia's past. While other histories of Asia have artfully demonstrated the distorting nature of such brittle nationalisms, by adopting a Himalayan-centered vantage point, this history of the Tibetan Muslims, and specifically the Lhasa Muslims, seeks to make visible what remained invisible under the more standard localist, nationalist, or global frames of analysis. ${ }^{13}$ When the Khache do appear in histories of Asia, they tend to be tinged by the preconceptions of the center. While such descriptions may have made them more intelligible to the distant imperial or national audiences thousands of miles away, they rarely corresponded to local Tibetan realities. In the essentialized orientalist narratives written by most Westerners, the Khache appear as non-Tibetan foreigners; when seen through the idiosyncratic religioethnic lens of the Chinese state they appear as Muslim Chinese Hui; or when viewed through an irredentist Indian nationalist perspective they are cast as members of the Kashmiri diaspora. In these accounts Khache appear as foreign, separate, and mutually unrecognizable rather than as indigenous, integrated, and familiar. So while a history of Tibetan Muslims on the surface appears insignificant and peripheral, it is precisely their centrality to Tibet's inter-Asian positioning that makes them an ideal subject. More than an isolated case study of a remote group, the history of the Tibetan Muslims allows startling new insights into the events of Asia's past. ${ }^{14}$ It is my hope that this study of the Tibetan Muslims will join the numerous studies that already highlight Tibet's diverse Mongolian, Bon, Newari, and Sherpa communities to further dispel the false notion of Tibet as a monolithic Buddhist society that remains so prominent in many mainstream accounts of Asia. ${ }^{15}$

\section{BEING TIBETAN WHILE MUSLIM}

A central obstacle to understanding the widespread presence of the Khache across Tibet has been the lack of clarity in previous studies between Tibetan Muslim permanent residents and Muslim sojourner communities within Tibet. As early as the eighth century, Islamic historians and geographers recorded numerous Muslim travelers, caravaneers, and merchants, even a mosque. ${ }^{16}$ While there is virtually no sustained documentary evidence-in Tibetan, Chinese, or any other languagethat traces the presence of the Muslim community prior to 1900, the fragmentary 
details that do survive suggest that until the late sixteenth century few Muslims resided in Tibet permanently.

Some evidence for this can be inferred from the fact that in Tibetan documents Muslims were typically designated by a variety of more or less pejorative terms. In religious texts such as the Kälacakra Tantra, Tibetans referred to Muslims as outsiders (Tib. kla klo), from the Sanskrit term mlecchas, or as nonbelievers (Tib. mustegs pa). Less literary Tibetan texts employed the term "foreigner" (Tib. phe rang), analogous to the Persian term farangi. Informally, the most common term was simply "white hats" (Tib. mgo dkar). ${ }^{17}$ All these terms emphasized on some level the Muslims' externality to Tibetan society and remained in use among educated Tibetans well into the twentieth century. ${ }^{18}$

By the fifteenth century, the Kashmiri were the first long-term Muslim residents in central Tibet. The Nepalese chronicle Vamshavalis notes that the first Kashmiri settlers in the Kathmandu valley were Muslim Kashmiris traveling between Kashmir and Lhasa. ${ }^{19}$ They were known as Khache, a term soon adopted by Tibetans to refer to any Tibetanized Muslim who resided within Tibet. Over time, this term widened even further semantically to include other Muslims who traced their origins to China and Central Asia. ${ }^{20}$

The confusion over the Khache typically falls into two categories. First, outsiders tended to adopt external, non-native terminologies that treated the Khache as foreign. Matters were further confused when foreign observers used such terms more or less interchangeably, sometimes calling the entire community "Ladakhi," at other times "Kashmiri," and, in Chinese, glossing any Muslim in Tibet as "Hui" - a blunder that few Tibetans would make. ${ }^{21}$ Representative of just such a proclivity, the Indian government in 1959 in negotiating with the People's Republic of China could not even settle on a single term for the Khache, sometimes referring to "Ladakhi and Kashmiri Moslems," then just simply "Kashmiri Moslems," and later "Kajis." ${ }^{22}$ The Chinese for their part tended to simply call them Hui, a highly ambiguous term that, depending on the context, could mean Chinese Muslim, any Muslim, or members of the state-defined nationality (Ch. minzu).

Second, attempting to gloss the Khache unequivocally as Tibetan Muslim is hindered by the fact that there exists no single Tibetan word in the premodern era that is equivalent to the modern word böpa (Tib. bod pa) used in Tibetan to refer to "Tibetan." To confuse the picture even further, in Tibetan a considerable amount of slippage existed between the religious and ethnic registers. In this way, in Tibetan, Khache could, and sometimes did, simply mean someone who practiced Islam. In other contexts, Khache acquired a more ethnic (or ethnoreligious) connotation, referring to those Muslims who had lived in central Tibet for generations, were native speakers of Tibetan, and, in many cases, had intermarried with local Tibetans. Finally, there remained a presumption among many nonTibetans that, even in the mid-twentieth century, the Khache were some sort of perpetual non-native. 


\section{TO BE TIBETAN MUSLIM}

It is often assumed that to be Tibetan is to be Buddhist and, axiomatically, that to be Muslim precludes one from being Tibetan. Yet from a Tibetan perspective, particularly in central Tibet, a Tibetan Muslim's non-Buddhist religious beliefs did not preclude him from being considered active and full participants in local Tibetan society. ${ }^{23}$ Nor were Tibetan Muslims a small or insignificant part of that society. By 1950, about 10 percent of Lhasa's roughly 30,000 lay inhabitants were Muslim. ${ }^{24}$ Lhasa alone had four mosques and two Muslim cemeteries, and by the early twentieth century mosques were present in every large central Tibetan city, including Shigatse, Gyantse, and Tsetang. ${ }^{25}$ During the Great Prayer Festival (Tib. smon lam) held at the start of the lunar new year, Khache were exempted from the strict rules governing the eating of meat imposed by the Buddhist monks who ruled Lhasa during the holiday. Similarly, Tibetan residents were tolerant of the early morning calls to prayer during the Muslim holy month of Ramadan. ${ }^{26}$

Despite the characterization of the Khache as perpetual non-natives in many foreign accounts of Lhasa, Tibetan Muslims lived as Tibetans among Tibetans by the early seventeenth century. Most historical records point to the earliest permanent Khache community as being established no later than the reign of the Fifth Dalai Lama (1617-82), when Tibet emerged as a major political force in Asia. The noted Tibet scholar José Cabezón suggests a strong linkage between the appearance of this Muslim community and the Fifth Dalai Lama's "invitation of the [nonTibetan] peoples" as "part of a larger policy of encouraging ethnic, cultural and economic diversity in Tibet." ${ }^{27}$ Given the Fifth Dalai Lama's leading role in establishing the Ganden Podrang, the political administration of central Tibet, and his interest in attracting a diverse array of artistic, intellectual, and religious influences to Tibet, it is not surprising that his rise to power marks the first period in which we see sustained evidence of a permanent Khache community. The vibrancy and political stability of the Fifth Dalai Lama's reign enabled the Khache to habituate themselves to Tibet and its culture in ways that transformed them from a simple immigrant community to one deeply integrated in Tibetan society. ${ }^{28}$

Khache can be found in almost every segment of Tibetan life. They were acknowledged as among the most literate and multilingual lay segment of the society. Tibetans, including the Fourteenth Dalai Lama, often praise the Khache for their linguistic abilities, particularly their mastering of the elaborate Lhasa dialect (Tib. zhe sa). They were also renowned for their multilingualism, with many Tibetan Muslims speaking Chinese, Hindi, Urdu, and Arabic, fostered by their prominent role in Tibet's trade with their Himalayan neighbors. What many regard as the most important secular Tibetan literary work ever written, the Khache Phalu's Advice on the Art of Living (Tib. Kha che pha lu'i 'jig rten las 'bras rtsis lugs kyi bslab bya), was penned by a Tibetan Muslim. ${ }^{29}$ As a result of these skills, Khache served as advisers to a succession of Dalai Lamas and operated as key brokers promoting Tibet's inter-Asian ties. 
By the twentieth century, central questions about the Khache's precise history, their position in Tibetan society, and their transnational identity remained obscured, ambiguous, and largely undocumented in Chinese, Indian, and Western sources as a result of external political claims on Tibet. The extended postindependence/post-liberation diplomatic tension between China and India usefully illustrates what Akhil Gupta has noted are the limits of modern concepts of citizenship to define those people who occupy "diversely spatialized, partially overlapping or non-overlapping collectivities." ${ }^{\circ 0}$ A history of the Tibetan Muslims highlights these early twentieth-century concerns while starkly demarcating the limits of the nonaligned, anti-imperialist, and pro-Asian solidarity movements of the 1950s. These movements defined the euphoric post-independence/ post-liberation period of India and China. The nature of Khache integration into Tibetan society also speaks to the large inter-Asian diasporic communities and to the strong financial and political ties these communities had to their ancestral countries of origin, primarily India and China.

As discussed in greater detail in later chapters, the traditional political, cultural, and commercial Himalayan relationships between Tibet and the neighboring states of Nepal, Bhutan, and Sikkim remained far more resilient than initially understood in Beijing and Delhi, which by the early 1950 s began to see Asia in a distinctly postcolonial, Cold War manner. Yet political unrest across the Himalayas played out in unexpected and nonlinear ways that suggest the Khache were not alone in their experience. The trepidation surrounding the People's Republic of China's occupation of Tibet and ongoing ambiguity surrounding China's ultimate goals in the Himalaya region created uncertainty that was manifested in a variety of ways from Kalimpong to Kathmandu and most visibly in Lhasa. Tracing these Himalayan connections, which continued to function years after the arrival of the People's Liberation Army in Lhasa, disrupts the supposedly stable, continuous, and overarching control often attributed to China's occupation of Tibet in 1950. The complex interrelationships, circulation, and transregional mobility so common in this area force us to look below the standard narratives of Indian and Chinese actions and throw into sharper relief the messy cosmopolitan interconnections that typified society across the Tibetan and Himalayan worlds well into the 1950 .

\section{KASHMIRI INDIAN OR TIBETAN CHINESE}

The meaning and power of such historical events are enhanced when seen through the eyes of individuals who lived them. With the Dalai Lama's flight to India and the subsequent 1959 March Uprising against Chinese control, the entire Tibetan Muslim community's status was irrevocably altered. Fearful of retribution, several Tibetan Muslim leaders, including one named Habibullah Naik, demanded that by virtue of their historical ties to Kashmir they be treated as foreign residents 
(like the Nepalese, Bhutanese, and other foreign residents of Lhasa who were also scrambling to be allowed to migrate back to their home countries in the wake of the 1959 March Uprising). The local Chinese authorities, deeply unnerved by any signs of dissent, arrested over a dozen Tibetan Muslim leaders, including Habibullah Naik, charging them with inciting the Khache to "claim a foreign nationality." ${ }^{31}$

The Khache's claims were not unusual for the period. Similar to many diasporic communities across Asia in the post-colonial period, the Khache asserted that their Kashmiri ancestry gave them the right to classify themselves as Indian citizens. They rallied as a community and began to assiduously avoid any actions that would identify them as Chinese. The difficulty arose in the very basic contradiction that most Khache had up until that point adamantly asserted themselves to be Tibetan. The Chinese state, playing its own game of self-deception, namely, that Tibet had always remained Chinese, saw the Khache's declaration of being Tibetan as tantamount to declaring oneself a citizen of the People's Republic of China.

Outside of Tibet, the Khache's situation was poorly understood. The New York Times in 1960 ran an article chronicling their plight with the headline "India's Traders held by Chinese." In the retaliatory Cold War logic of the period, many assumed the Khache were Indian nationals simply caught out by the abruptly shifting political winds. As the article was quick to point out, however, the "Indian traders" were not unequivocally Indian citizens. Described by the Indian government as "Kashmiri Muslims," the group arrested by the Chinese was part of a community that had resided in Tibet for generations and by their own admission had "never carried [Indian] travel documents and identification certificates," yet now "wanted to register themselves as Indian nationals." ${ }_{32}$

The New York Times' terminological ambiguity is unsurprising. By virtually every measure, Habibullah Naik was Tibetan. Born in Lhasa at the turn of the twentieth century, he grew up living above his store in central Lhasa where his family had resided for generations. He spoke the pure Lhasa dialect of Tibetan, dressed in Tibetan clothing, and revered the Dalai Lama as the leader of Tibet. He and the other Khache, prior to 1950, had long been considered Tibetan subjects by the Tibetan government. Tibetan Buddhist pilgrims circumambulating the sacred inner pilgrimage circuit streamed past the front gates of the mosque where he prayed daily. His relatives had, over the generations, intermarried with Tibetans, blurring any lingering divisions-physical, ancestral, or imagined-between his Buddhist and Muslim neighbors. ${ }^{33}$ Until the Dalai Lama's decision to flee to India in 1959, Habibullah Naik was undeniably Tibetan and was treated as such by the Tibetan government and his Tibetan neighbors. In order to verify their Kashmiri ancestry, the Tibetan Muslim leaders were informed by the Chinese authorities that all claims of foreign citizenship would require "fresh documentary proof." ${ }_{4}$ When the Chinese government's stern cautions went unheeded, they deemed Naik and other Khaches' efforts to declare themselves foreign as seditious activities and 
imprisoned them. The Tibetan Muslim community as a whole faced daily harassment, middle-of-the-night interrogations, and starvation-level rations.

As Naik and his fellow Khaches had discovered, the ability of Himalayan states like Tibet, Nepal, Bhutan, and Sikkim to defy the hardening boundaries of postliberation and postcolonial Asia was quickly coming to an end. Under both international pressure from India and domestic pressure to resolve the diplomatic crisis, the Chinese government abruptly acquiesced. All Tibetan Muslims who "voluntarily stat[ed] that they wanted to change their nationality from Chinese to Indian" would be allowed to resettle in India. ${ }^{35}$ By late 1960, nearly one thousand Khache demonstrated adequate proof of their Kashmiri, and thus "Indian," ancestry and were issued exit permits.

The Chinese did not extend this amnesty to individuals, like Naik, who had committed offenses against the state..$^{36}$ However, on March 29, 1961, with no explanation, the Chinese made a single exception and released Naik. Alone of those arrested, he was escorted by Chinese officials from his Lhasa prison cell to a truck waiting outside the prison and transported to the southern Tibetan border town of Dromo (Ch. Yadong). There he joined one of the last convoys of Nepalese, Khaches, and other Tibetans, who by virtue of their foreign ancestry were issued Chinese exit visas and allowed to leave Tibet after the violent crackdown on 1959 March Uprising. Habibullah Naik would never again step foot in Tibet. He and the other Khaches crossed into India, acquired Indian citizenship, and began their new lives.

The emigration of Habibullah Naik and several thousand other Khaches offers a little-known coda to the history of the Khache in central Tibet. On the surface, the Khaches' return to India and Kashmir is founded on the false premise that the Khache had retained their distinct and separate Kashmiri identity across several centuries and thus returning to their country of origin. But under closer examination, the 1960 Khache Incident is only the most recent example of the Khache challenging the ostensibly hard boundaries of imperial/national identity and subjecthood/citizenship. A history of the Khache experience in central Tibet underscores how the ethnic, religious, and political categories of modern Asian nationhood conceal significant dimensions of Asia's past and the significant relationships between numerous Himalayan states and Tibet up to the present.

Habibullah Naik's assertion that he should be allowed to declare himself a citizen of India emerged out of a much larger constellation of events, modalities, and peoples than just the proximate issues surrounding the 1959 March Uprising in Lhasa. The Khaches' demands for Indian citizenship strike at the heart of how postcolonial regimes erected new boundaries of national citizenship at variance with those inherited from the earlier, imperial regimes. Numerous diasporic communities were confronted with a choice between allegiance to their ancestral home or citizenship in a newly formed nation-state that had emerged out of the former colonial state where their families had lived for generations. 
Nor was this a question only for small populations like the Khache, Nepalese, or Bhutanese who discovered themselves at odds with the Chinese government in Tibet. As the sociologist Itty Abraham has pointed out, "Within Asia, the presence of Indians and Chinese outside their traditional homelands had been a part of the local social and cultural and economic landscape for long enough that their nationality was quite ambiguous." ${ }^{37}$ The difference for the Khache was the fact that simmering tension between these "foreign" communities and the "local" populations was not the primary factor in their decisions. Instead, the decision of many Tibetan Muslim individuals to declare themselves Indian was a direct result of the Chinese government's questioning of the community's political loyalties in the wake of India offering the Dalai Lama asylum in 1959. In this light, the question of the Khaches' national identity, or loyalty, offers an alternative understanding of inter-Asian relations. The Khaches' predicament demonstrates the experience of many Asians when questions of ancestry and citizenship were imperfect solutions to the question of national identity in a Himalayan context.

To appreciate the complexities of the Khache past we need, on the one hand, to pay attention to the processes that reterritorialized, relabeled, and renationalized the Khache as "Kashmiri Muslims." On the other hand, we must examine the manner by which the Khache had, in time, space, and memory, become incontrovertibly Tibetan. The history and memory of the Khaches' past have interacted in unusual ways with mainstream Tibetan and Asian historiography, making it a particularly elusive narrative to reconstruct.

\section{ARRESTED HISTORIES?}

Even the briefest introduction to the Khache demonstrates that to grasp their complex position is to grapple with multiple overlapping misconceptions. Just as "Kashmiri" was an imperfect term to refer to the Khache living in Tibet, across Asia questions were being asked about the status of the resident "Indian" or "Chinese" populations who had resided outside their country of origin, in many cases for generations.

The seemingly innocuous labels for such communities hid highly fraught undercurrents and prejudices. The depth of emotion that such terms elicited in the postcolonial era caught many unaware. For as Anna Lowenhaupt Tsing reminds us:

Words in motion surprise us. Their far-flung antics interrupt conventional intellectual history, with its assumption of stable genealogies of thought. They are spread too far for the boundaries of national history; they ricochet too widely to follow strictly colonial geographies. Words in motion urge us to consider multiple linguistic and cultural legacies in dialogue. ${ }^{38}$

The power of the Tibetan Muslims to serve as an analytical lens lies in its ability to capture in unexpected ways the changing relationship of space and identity that 
accompanied the decolonialization and reterritorialization of Asia across the nineteenth and twentieth centuries. In this light, the evolution of the Khache identity is emblematic of a much broader dilemma occurring across postcolonial Asia over hardening conceptualizations of "nation" and "citizen."

If the Khaches' transnational and inter-Asian positioning masked their Tibetan identity, Carole McGranahan's concept of arrested histories provides a constructive way to delineate how their position in Tibet's history remains intact but inaccessible. The Khaches' historical position in Tibet parallels that of the Tibetan people more generally, in that it "is more complicated than a sweeping under the rug of inconvenient past and politics; it is a delay or postponement of histories for the present only."39 Not abandoned or erased, the Khache have always remained in plain sight, yet never quite in focus. They have been screened off within the official chronicling of the past since they do not fit comfortably in the historical narrative of Tibet.

It is in this awkward space-never entirely ignored but never fully integratedthat the Khache have persisted in the historical narrative for over three centuries. Virtually every Western visitor who passed through Tibet, from the earliest Jesuits to Heinrich Harrer, Lhasa's most famous foreign resident, noted in some manner the presence of the Khache. ${ }^{40}$ Chinese sources follow a similar pattern, recording the size and number of mosques in Lhasa, describing Khache routes, and enumerating the Khache communities across Tibet. ${ }^{41}$ To grasp the complex nature of the Tibetan Muslim community, one must first address the means by which the Khache so successfully integrated themselves into Tibetan society. How they retained the hybrid influences of Tibet's external neighbors-South Asia, Central Asia, and China-as well as Tibet's complex internal intricacies is part of this history. While the Tibetan Muslim communities across the eastern Tibetan regions of Amdo and Kham shared many qualities with those described below, above all else, this study seeks to provide an alternative history of Himalayan Asia that is positioned in and around the experiences of the Lhasa Khache.

While this work is the first book-length study of the Lhasa Khache, it is not a history of Islam in Tibet. Rather it engages the cosmopolitan nature of the Khache by attempting to situate them within Tibet and its relationship across the Himalayan world. Although it explores many new sources, its value lies less in the unearthing of new manuscripts or detailing hitherto unexplored religious networks than in considering the latent intersectional identity of the Khache as a means to offer a new approach to Tibet's past and look with fresh eyes upon a place and era we believed we already knew quite well. 